NOTES

\title{
Counterion Binding of Ionene Polymers in Water-Acetone Mixtures by Means of Activity Measurement
}

\author{
Shinobu KODA, Ryuki HASHITANI, and Hiroyasu NOMURA* \\ Department of Chemical Engineering, School of Engineering, Nagoya University, \\ Furo-cho, Chikusa-ku, Nagoya 464, Japan
}

(Received September 25, 1987)

\begin{abstract}
KEY WORDS Activity Coefficient / Ionene / Water-Acetone Mixture / Counterion Binding / Polyelectrolyte
\end{abstract}

Electrostatic field near polyions plays very important role in the counterion binding of polyelectrolytes in solutions. If a mixed solvent system is used instead of aqueous, one can control the electrostatic field near polyion systematically by changing the dielectric constant of solution. Therefore, the study of polyelectrolyte in mixed solvents will give very useful information. Most polyelectrolytes, such as poly(acrylate) and poly(styrenesulfonate), have very low solubility in the low dielectric media. As ionene polymer consists of quarternary ammonium ion, it is fairly soluble in nonaqueous media. Besides, the charge density of ionene polymer can be controlled easily by changing the distance between two charges, that is, the number of methylene units.

The activity coefficient of counterion is one of the useful thermodynamic quantities to understand ion binding of polyelectrolyte solution. Counterion binding on polyions makes the activity coefficient of counterion lower. In this paper, we report the experimental results of activity coefficient of chloride ion in aqueous solutions and $30 \mathrm{wt} \%$ acetone-water mixtures involving ionene polymers and discuss the counterion binding of ionene polymers in solution.

\footnotetext{
* To whom correspondence should be addressed.
}

Ionene polymers used were 3,3- and 6,6ionene chlorides which were synthesized by the method reported by Rembaum et al. ${ }^{1}$ The products were precipitated in a large amount of acetone, filtrated and washed several times with acetone. The sample were dried for 24 hours in a vacuum oven at $40^{\circ} \mathrm{C}$. The molecular weights of these ionenes were 17,200 for 3,3-ionene and 18,600 for 6,6-ionene, respectively, which were determined by viscosity measurement in $0.4 \mathrm{moll}^{-1} \mathrm{KBr}$ solution. ${ }^{1}$

EMF measurements were carried out using a combination chloride electrode (Orion, 9617B) a digital ion meter (Orion, 701A). The activities of chloride ion were determined by calibration method. In order to obtain the calibration curve, the activity of chloride ion was assumed to be equal to the mean activity of $\mathrm{NaCl}$. The values for aqueous solutions were found in the text, ${ }^{2}$ but those for wateracetone mixed solvent systems were calculated by modified Debye-Huckel equation ${ }^{2,3}$;

$$
\log f_{ \pm}=-0.743_{1}\left(\frac{\sqrt{I}}{1+\sqrt{I}}-0.3 I\right)
$$

where $f_{ \pm}$is the mean activity coefficient of $\mathrm{NaCl}$ on mole fraction scale and $I$ is ionic strength. Calibration was made before and 

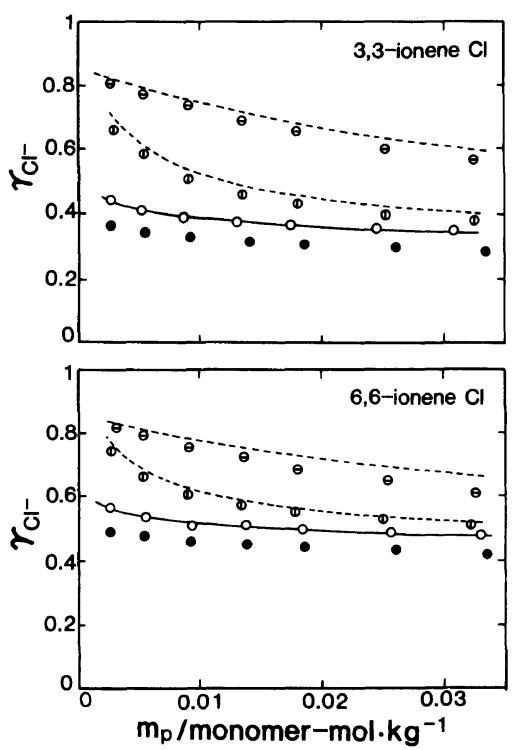

Figure 1. Activity coefficient of chloride ion solution of 3,3- and 6,6-ionenes. Aqueous solution: $\bigcirc$, no salt; (1), $0.003 \mathrm{NaCl} \mathrm{mol} \mathrm{kg}{ }^{-1} ; \ominus, 0.03 \mathrm{NaCl} \mathrm{mol} \mathrm{kg}^{-1}$. Acetone-water mixture: $\mathbf{O}$, no salt. The dashed lines are calculated by eq 2 and the solid lines are drawn by fitting method.

after each run, and the differences in potential were within $1.0 \mathrm{mV}$. The range of the concentration of ionenes were from 0.003 to $0.030 \mathrm{~mol} \mathrm{~kg}^{-1}$. All measurements were carried out at $25.0^{\circ} \mathrm{C}$.

Figure 1 shows the plot of activity coefficient of chloride ion, $\gamma_{\mathrm{Cl}^{-}}=a_{\mathrm{Cl}^{-}} /\left(m_{\mathrm{p}}+m_{\mathrm{s}}\right)$, vs. concentration of ionene polymer, $m_{\mathrm{p}}$ (monomer mol kg$\left.)^{-1}\right)$, where $m_{\mathrm{s}}\left(\mathrm{mol} \mathrm{kg} \mathrm{kg}^{-1}\right)$ is the concentration of $\mathrm{NaCl}$. As shown in Figure 1, the values of $\gamma_{\mathrm{Cl}^{-}}$in both aqueous solution and mixed solvent systems without $\mathrm{NaCl}$ are very small, comparing with mean activity coefficient of $\mathrm{NaCl}, \gamma_{ \pm}$in $\mathrm{NaCl}$ solution without polymer (the values of $\gamma_{ \pm}$are $0.98-0.85$ for the aqueous solution and $0.91-0.79$ for the mixed solvent system in this work). The large lowering of $\gamma_{\mathrm{Cl}^{-}}$from $\gamma_{ \pm}$is considered as the decrease of the amount of the free counterion. In other words, the counterion binding occurs.

The dashed lines in Figure 1 are calculated by the following;

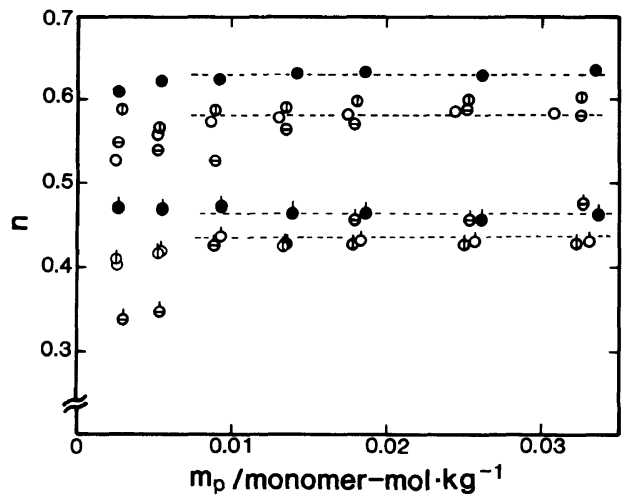

Figure 2. A fraction of counterion bound to a polyion for 3,3- and 6,6-ionenes. 3,3-Ionene: $\bigcirc$, ro salt; (1), 0.003 $\mathrm{NaCl} \mathrm{mol} \mathrm{kg} \mathrm{kg}^{-1}, \ominus, 0.03 \mathrm{NaCl} \mathrm{mol} \mathrm{kg} \mathrm{kg}^{-1}$ in aqueous solution; $\bigcirc$, no salt in $30 \mathrm{wt} \%$ acetone-water mixture. 6,6-Ionene: $\zeta$, no salt; $\phi, 0.003 \mathrm{NaCl}$ mol kg-1; $\ominus$, $0.03 \mathrm{NaCl} \mathrm{mol} \mathrm{kg} \mathrm{kg}^{-1}$ in aqueous solution; $\phi$, no salt in $30 \mathrm{wt} \%$ acetone-water mixture.

$$
\begin{aligned}
\gamma_{\mathrm{Cl}^{-}}= & \left(m_{\mathrm{p}} \gamma_{\mathrm{Cl}^{-}}\left(m_{\mathrm{s}}=0\right)\right. \\
& \left.+m_{\mathrm{s}} \gamma_{ \pm}\right) /\left(m_{\mathrm{p}}+m_{\mathrm{s}}\right),
\end{aligned}
$$

where $\gamma_{\mathrm{Cl}}-\left(m_{\mathrm{s}}=0\right)$ is the activity coefficient of chloride ion in the aqueous solution without $\mathrm{NaCl}$. As shown in Figure 1, the calculated values are roughly in agreement with the experimental values and thus the additivity rule of the activity coefficient almost holds in our experiments.

Assuming that the activity coefficient of free chloride ions in solution of ionene polymer is equal to the mean activity coefficient of $\mathrm{NaCl}$ in solution without polyelectrolyte, we can define a fraction of chloride ion bound on a polyion as

$$
n=\left(m_{\mathrm{p}}+m_{\mathrm{s}}-a_{\mathrm{Cl}}-/ \gamma_{ \pm}\right) / m_{\mathrm{p}} .
$$

The plots of $n v s . m_{\mathrm{p}}$ are given in Figure 2 . All the $n$ values are almost independent of polymer and added salt concentrations investigated here within experimental error. $n=$ $0.44 \pm 0.02$ for 6,6 -ionene and $n=0.58 \pm 0.02$ for 3,3-ionene, respectively. Polyelectrolyte chain in aqueous solution expands by strong electrorepulsive force and conformation of polyion changes with concentrations of poly- 
mer and added salt in solutions. However, $n$ is almost independent of concentrations of polymer and also added salt. Therefore, the counterion binding is not affected largely by the changes of conformation of polyion.

As is seen in Figure 2, the values of $n$ for both 3,3- and 6,6-ionenes in water-acetone mixture are larger than those in aqueous solutions, respectively. As dielectric constant of $30 \mathrm{wt} \%$ water-acetone mixture is 61.04 , the electrostatic field near polyions in wateracetone mixture is stronger than that in aqueous solution. Thus a fraction of the counterion binding is larger in acetone-water mixtures than in aqueous solutions.

A linear charge parameter, $\xi=q^{2} / \varepsilon k T b$, in Manning's counterion condensation theory, ${ }^{4}$ is 0.82 for 6,6 -ionene in aqueous solution and 1.05 for that in $30 \mathrm{wt} \%$ acetone-water mixture. Form the view point of Manning's theory, it may be expected that the counterion binding does not occur in aqueous solution of 6,6ionene because of $\xi<1$. From the measurements of the mean electropholitic mobility, Klein and Ware indicated that the counterion binding in the case of 6,6-ionene chloride in methanol-water mixtures does not occur until $\xi=1$, i.e., below ca. $30 \mathrm{wt}^{\mathrm{o}} \%$ of methanol. ${ }^{5}$ However, as shown in Fig. 1, the activity coefficient lowering due to counterion binding were clearly observed even in the case of 6,6ionene polymer in aqueous solutions. The counterion binding in the region of $\xi<1$ was also recognized for calcium acrylamide-acrylic acid copolymer ${ }^{6}$ and chitosan chloride ${ }^{7}$ from the measurements of the counterion activity coefficients.

The measurements of the different physical quantities provide the different degree of counterion binding, as indicated in previous paper. ${ }^{8}$ The degree of counterion binding estimated from activity coefficient provides the total amount of the counterions bound to polyion; one is due to the specific interaction which is accompanied with the changes of the hydration volume and the other due to ionic atmospheric interaction.

\section{REFERENCES}

1. S. P. S. Yen, D. Casson, and A. Rembaum, "WaterSoluble Polymers." N. M. Bikales, Ed., Plenum Press, New York, N, Y., 1973, p 291.

2. R. A. Robinson and R. H. Stokes, "Electrolyte Solutions," 2nd Ed., Butterworths, London, 1959.

3. C. W. Davies, "Ion Association," Butterworths, London, 1962, p 41.

4. for example, G. S. Manning, Quart. Rev. Biophys., 11, 179 (1978).

5. J. W. Klein and B. R. Ware, J. Chem. Phys., 80, 1334 (1984).

6. M. Kowblansky and P. Zema, Macromolecules, 14, 166, 1448 (1981).

7. C. A. Kienzie-Sterzer, G. Bakis, D. RodriquezSanchez, and C. K. Rha, Polym. Bull., 11, 185 (1984).

8. S. Koda, H. Nomura, and M. Nagasawa, Biophys. Chem., 23, 147 (1985). 